\title{
Transcatheter Closure of Atrial Septal Defect and Balloon Pulmonary Valvuloplasty with Inoue Balloon in Adult Patients.
}

\section{Chandra Mani Adhikari, Kiran Acharya, Amrit Bogati, Anjana Acharya, Dipanker Prajapati.}

Department of Cardiology, Shahid Gangalal National Heart Center, (SGNHC), Bansbari, Kathmandu, Nepal.

Corresponding Author:

Chandra Mani Adhikari

Department of Cardiology, Shahid Gangalal National Heart Center, (SGNHC), Bansbari, Kathmandu, Nepal.

E-mail: topjhap@gmail.com

ORCID ID NO: https://orcid.org/0000-0001-5811-9977

Submitted date: $19^{\text {th }}$ December 2020

Accepted date: $18^{\text {th }}$ February 2021

Cite this article as: Adhikari C M, Acharya K, Bogati A,et al. Transcatheter Closure of Atrial Septal Defect and Balloon Pulmonary Valvuloplasty with Inoue Balloon in Adult Patients. Nepalese Heart Journal 2021; Vol 18 (1): 61-64.

Abstract

\begin{abstract}
Secundum type atrial septal defect combined with pulmonic stenosis is a relatively uncommon condition in adult patients When occurred separately they can be treated with transcatheter intervention. When they occur together ideal treatment option is not clear. We report a case of combined percutaneous pulmonary valvuloplasty done with the Inoue balloon and transcatheter atrial septal defect closure in an adult patient.
\end{abstract}

Keywords: Adult; Atrial Septal Defect Occlusion; Combined Percutaneous; Balloon Pulmonary Valvuloplasty.

DOI: https://orcid.org/10.3126/njh.v18i1.36790

\section{Introduction}

Secundum type atrial septal defect (ASD) combined with pulmonic stenosis (PS) is a relatively uncommon condition in adult patients. ${ }^{1}$ Transcatheter ASD closure and Balloon Pulmonary Valvuloplasty (BPV) for isolated secundum ASD and isolated PS are the preferred treatment option for adults when anatomically feasible. ${ }^{2}$ When these conditions occur together ideal treatment plan is still a matter of debate. There are several reports ${ }^{1,3,4,5,6,7,9}$ of patients being treated by a transcatheter technique, either staged or combined, with no clear agreement as to which procedure should be performed first. ${ }^{3,4,5,6}$ Tyshak balloon is most commonly used for BPV. There are cases reports of BPV done with the Inoue balloon. ${ }^{8,9,10,11}$ We report a case of combined BPV with the Inoue balloon and transcatheter ASD closure in patients with ASD and PS in an adult patient.

\section{Case Report}

A 22-year-old woman referred for intervention with the diagnosis of ASD secundum and PS. At clinical evaluation, she was diagnosed with ASD secundum and severe pulmonary valve stenosis.
Trans-thoracic Doppler echocardiography showed dilated Right Atrium (RA) and Right Ventricle (RV) with a (20-mm) ostium secundum ASD and a gradient $(54 \mathrm{mmHg})$ across the pulmonic valve as shown in Fig.1. Pulmonary valve annulus was $21 \mathrm{~mm}$. Trans esophageal echocardiogram (TEE) was done which showed maximum ASD size of $20.8 \mathrm{~mm}$ with absent Aortic rim with all other rims present shown in Fig. 2 and 3. Patient was planned for BPV followed by transcatheter ASD closure. BPV was attempted with Tyshak balloon $(6 \times 24)$, balloon was unstable, caused bradycardia and hypotension due to long inflation and deflation time. BPV was attempted with the inoue PTMC balloon $(24 \mathrm{~mm})$ shown in Fig. 4. After the BPV gradient across the pulmonic valve decreased to $31 \mathrm{mmHg}$ as shown in Fig 5. Patient was discharged and called for transcatheter ASD closure after a month. Patients underwent transcatheter ASD closure with $28 \mathrm{~mm}$ Amplatzer septal occluder shown in Fig.6. At one year of follow up gradient across the pulmonic valve was $15 \mathrm{mmHg}$. RA and RV was normal in size. No tricuspid regurgitation shown in Fig.7 and 8.

(a) Nepalese Heart Journal. Nepalese Heart Journal retain copyright and works is simultaneously licensed under Creative Commons Attribution License CC - By 4.0 that allows others to share the work with an acknowledge of the work's authorship and initial publication in this journal 
Figure 1: Gradient across Pulmonary Valve before BPV.

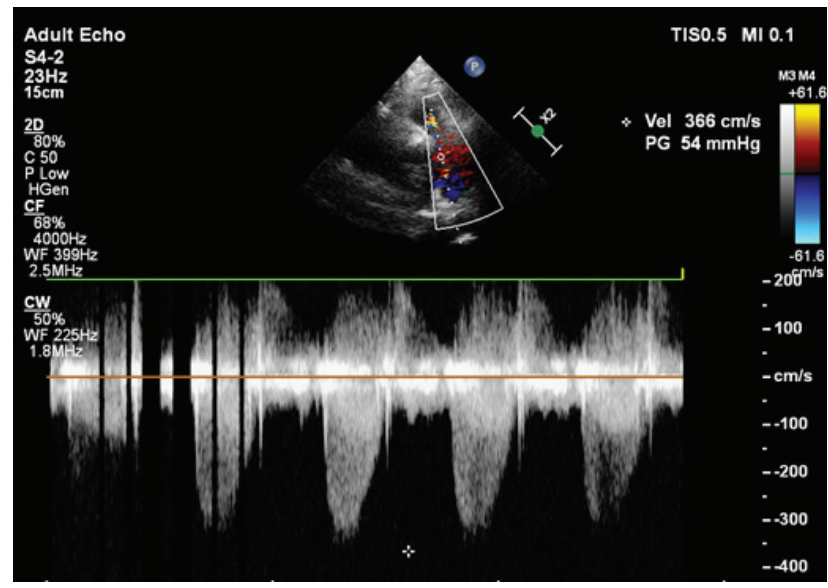

Figure 2: ASD in TEE Bi-Caval View.

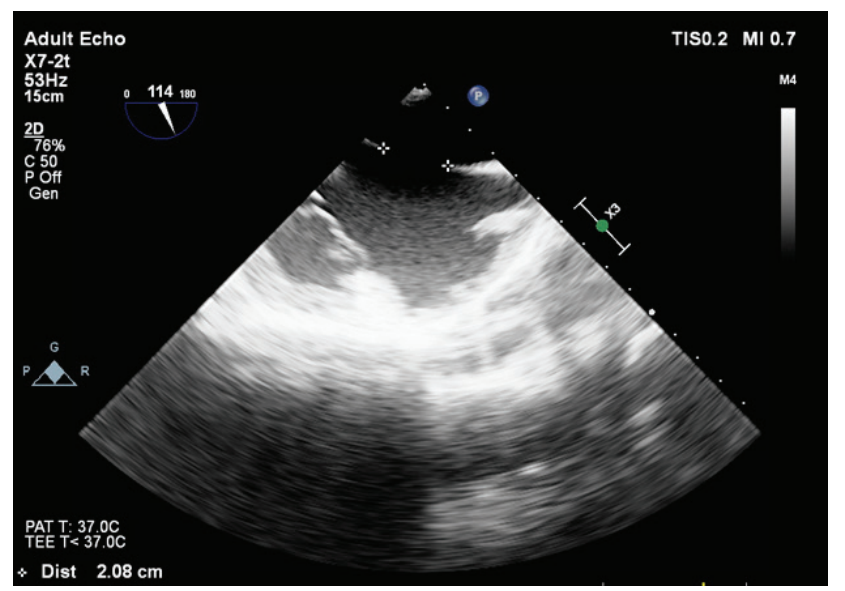

Figure 3: ASD in TEE Short Axis View.

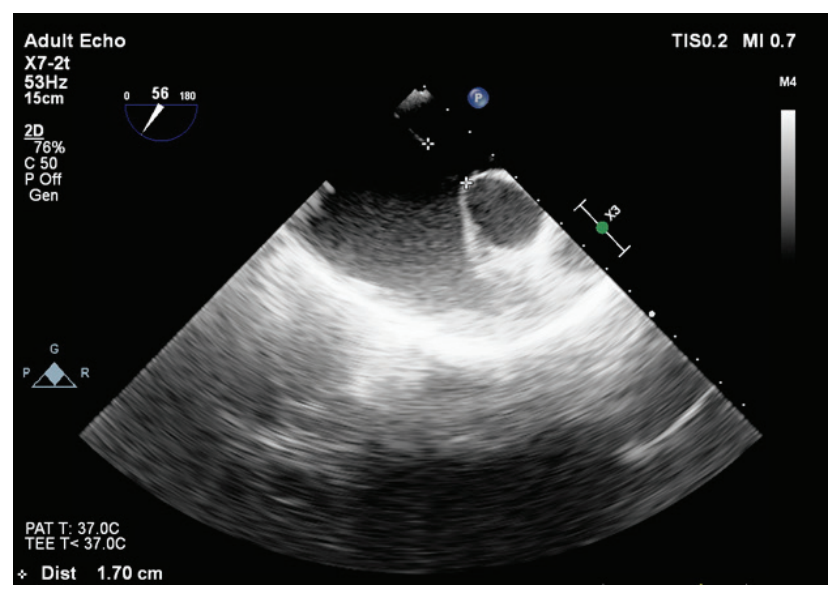

Figure 4: BPV with Inoue Balloon.

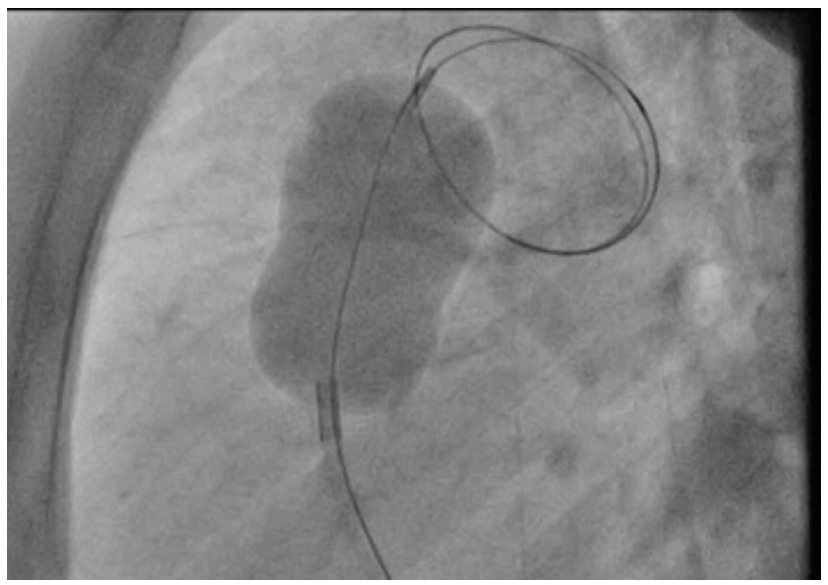

Figure 5: Gradient across Pulmonary Valve after BPV.

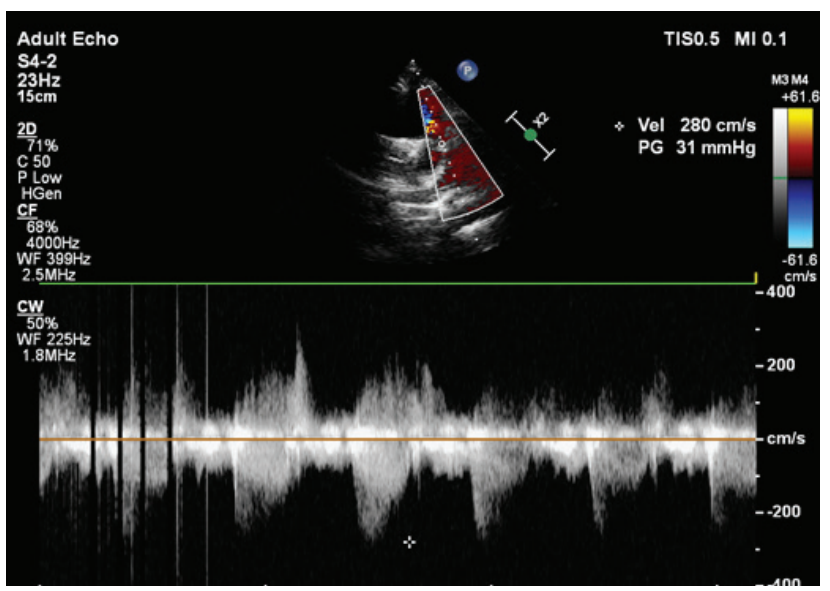

Figure 6: Post ASD Device Closure.

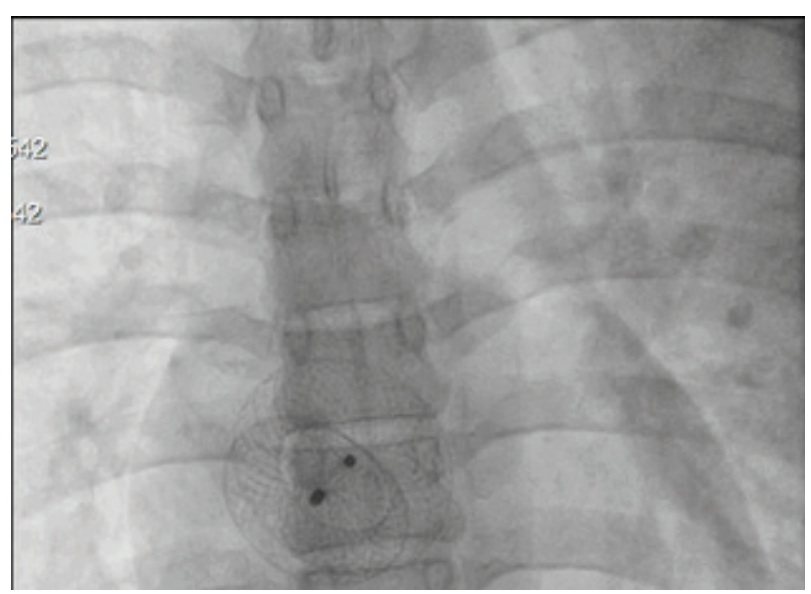


Figure 7: Gradient across Pulmonary Valve at One year follow up.

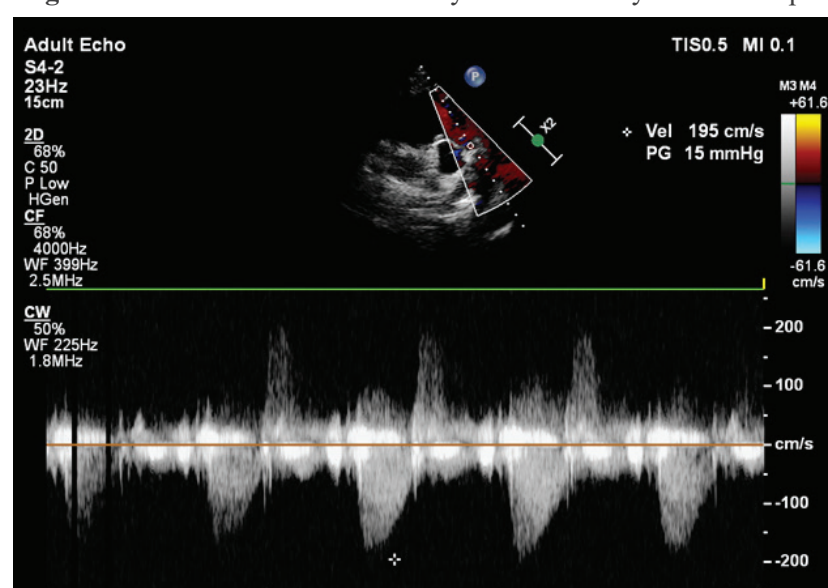

Figure 8: Echocardiogram at One year follow up.

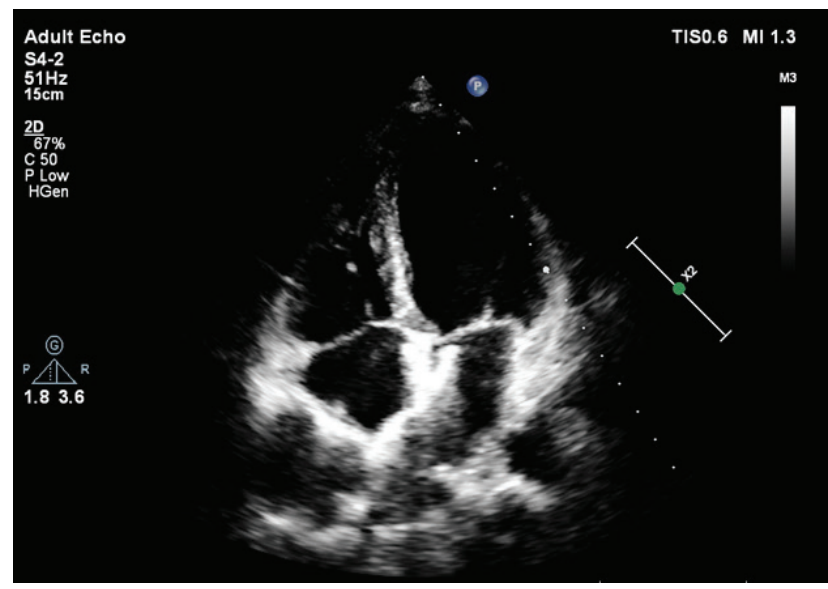

\section{Discussion}

Rapid advances in interventional cardiology have changed the therapeutic modality for many patients with complex congenital heart disease. ${ }^{7}$ Several reports describe transcatheter approach for the treatment of combined secundum type ASD and PS. They vary in answering the question which defect should be treated first and whether the procedures should be staged or combined., Treating the ASD first should eliminate the left to right shunt and thus also the right ventricle volume overload and possibly lower the pressure gradient across the pulmonic valve, enabling one to reassess the pulmonic stenosis severity. On the other hand, addressing the pulmonic stenosis first lowers the peri-procedural risk of ASD device dislodgement. ${ }^{1}$

In our case we used Inoue balloon for BPV. With Tyshak balloon, balloon instability and long inflation and deflation time causes bradycardia and hypotension. ${ }^{7,8,9}$ Inoue balloon has relatively short and flexible balloon and a rapid inflation and deflation cycle (approximately 4-5s) allowing fast hemodynamic recovery. It also allows graded dilations by increasing the size of the same balloon, thus preventing cumbersome exchanges of balloons. ${ }^{8}$ It has a unique property of self-positioning, enabling it to anchor at the pulmonary valve during inflation, thus preventing abrupt forward movement and damage to the Pulmonary Artery (PA). ${ }^{9,10}$ The risk of overdilation of the pulmonary valve is also minimized due to the size-adjustable nature of the Inoue balloon making stepwise dilation possible. ${ }^{11} \mathrm{BPV}$ with the Inoue balloon makes the procedure much more convenient.

The major advantages of combination of transcatheter ASD closure and BPV for patients with ASD and PS are the short hospital stage, absence of thoracotomy, open heart surgery and admission to an intensive care unit, thus avoiding subsequent surgical scar and post-operative pain. The major limitation in this case report is: as this case was reported in a retrospective manner, we cannot provide the hemodynamic studies.

\section{Conclusion}

Combined transcatheter ASD closure and BPV is feasible and effective and achieve a satisfactory outcome. BPV with Inoue balloon is convenient and effective.

Disclosure: The authors who were members of the editorial team were not involved in any steps in the editing/publication process.

\section{References}

1. Pavol T, Katerina L, Petra A, et al. Combined percutaneous treatment of atrial septal defect and pulmonic or aortic stenosis in adult patients. Arch Med Sci 2010; 6, 6: 976-980. https://doi.org/10.5114/aoms.2010.19312 PMid:22427776 PMCid:PMC3302714.

2. Baumgartner H, Backer JD, Babu-Narayan SV, et al. 2020 ESC Guidelines for the management of adult congenital heart disease: The Task Force for the management of adult congenital heart disease of the European Society of Cardiology (ESC). Endorsed by: Association for European Paediatric and Congenital Cardiology (AEPC), International Society for Adult Congenital Heart Disease (ISACHD). European Heart Journal, 2021; 42(6,7):563-645. https://doi.org/10.1093/eurheartj/ehaa554 PMid:32860028

3. Wahl A, Windecker S, Misteli M, et al. Combined percutaneous pulmonary valvuloplasty and atrial septal defect closure for pulmonary valvular stenosis and associated secundum atrial septal defect in an adult. Catheter Cardiovasc Interv 2001; 53: 68-70.

https://doi.org/10.1002/ccd.1132 PMid:11329221

4. Vera JA, Nounou M, Kern M . Staged Percutaneous Atrial Septal Defect Closure and Pulmonic Balloon Valvuloplasty in an Adult with Congenital Heart Disease. Catheter Cardiovasc Interv 2008; 72: 416-23. https://doi.org/10.1002/ccd.21612 PMid:18727123

5. Yip WC, Chan KY, Godman MJ. Simultaneous trans- catheter valvuloplasty and Amplatzer septal occlusion for pulmonary valvar stenosis and secundum atrial septal defect. Ann Acad Med Singapore 1998; 27: 578-81.

6. Alfonso Medina, José Suárez de Lezo, Antonio Delgado, et al. Combined Percutaneous Atrial Septal Defect Occlusion and Pulmonary Balloon Valvuloplasty in Adult Patients. Tex Heart Inst J 2000; 27: 216-7.

7. Mostafa Behjati-Ardakani, Seyed Mahmood Sadr-Bafghi, Abbas Andishmand. Combined Transcatheter Closure of Atrial Septal Defect and Pulmonary Valve Balloon Dilation Acta Medica Iranica, 2012; 50(10): 710-712. 
8. Surender Deora, Chirayu Vyas, Sanjay Shah, et al. Percutaneous balloon pulmonary valvuloplasty: A modified over-the-wire Inoue balloon technique for difficult right ventricular anatomy. Indian Heart Journal 2014; 166:211-213. https://doi.org/10.1016/j.ihj.2013.12.010 PMid:24814118 PMCid:PMC4017389.

9. Lau KW, Hung JS, Wu JJ, et al. Pulmonary valvuloplasty in adults using the Inoue balloon catheter. Cathet Cardiovasc Diagn. 1993; 29:99-104.

https://doi.org/10.1002/ccd.1810290203 PMid:8348609
10. Patel TM, Dani SI, Shah SC, et al. Inoue balloon pulmonary valvuloplasty using a 'free-float technique'. J Invasive Cardiol.1996; 8:374-377.

11. Vinay K. Bahl, Subhash Chandra, Harbans S. Wasir. Pulmonary valvuloplasty using Inoue balloon catheter. International Journal of Cardiology 1994; 45:141- 143. https://doi.org/10.1016/0167-5273(94)90271-2 